the loin compressed it can be retained below the thumb for as long a time as the examiner pleases.

The right hand, previously passive, is now used to palpate the kidney in its abnormal position. When the examination is finished the right hand gently pushes the kidney upwards whilst the thumb of the left hand is raised to allow of its passage. As the organ returns the thumb can be seen to iide over it and the peculiar slipping sensation associated with its replacement is very noticeable. The use of the second hand, however, is not necessary if mobility alone is in question, and by using a hand for each loin both kidnevs, if sufficiently moveable, can be fixed below the thumbs. Sometimes the sharp compressing movement nips the kidney exactly at its centre and it may then be held in this position, though this usually causes some pain.

The application of the method is rendered easier by the fortunate possession of long fingers, and particularly of a long thumb, but it undoubtedly has the advantage of enabling the kidney to be felt throughout late inspiration and early expiration ; for although, as Mr. Morris points out, a deep inspiration produces a hardening and bulging forwards of the anterior abdominal wall, yet firm compression is able in most cases to resist this so long as the patient breathes quietly and not spasmodically. By using this method it will be found that (in women at least) the lower end of the right kidney can practically always, and that of the left kidney nearly always, be easily felt on deep quiet inspiration. My experience is limited to the examination of women, but in them I should certainly hesitate to call any kidney moveable above the upper end of which I found it impossible to get my thumb by using this manouvre.

I am, Sirs, yours faithfully,

W. F. VICTOR BONNEY, M.D., M.S. Lond, Assistant Physician, Chelsea Hospital for Women. Deronshire-street, W., Dec. 14th, 1901.

\section{CANCER AMONG HINDOOS.}

To the Editors of THE LANCET.

SIRs,--In THE LANCET of Oct, 5th, p. 939. Mr. C. B. Keetley, writing upon the subject of cancer, states that he had been informed by Dr. C. N. Saldanha that "Hindoos suffer comparatively little from cancer." Upon this statement of the comparative immunity of Hindoos from cancer both Dr. Saldanha and Mr. Keetley base certain arguments regarding the prophylaxis of the disease. I do not know in what part of India Dr. Saldanha gathered the experience upon which he Wases his opinion, but his statement is certainly not correct so far as Southern India is concerned. On the contrary, in this part of India cancer is very prevalent amongst Hindoos and much more so than amongst Mahomedars. In the wards of the Madras General Hospital cases of cancer affecting Hindoos are almost always to be found. At the time that I write I have three Hindoos in my wards suffering from this disease. Indeed, so common is the affection here that there are few diseases that our students are so familiar with when they leave college as cancer. The disease is most frequently seen in the mouth, affecting the inner side of the cheek. Cancer of the penis is also very common, as well as cancer of the uterus and breast.

I am, Sirs, yours faithfully,

Madras, Nor. 28th, 1901

J. Maituand, M.D. Edin.

Lieutenant-Colonel, I.M.S.

\section{ADMINISTRATION OF CHLOROFORM.}

\section{To the Editors of THE LANCET:}

SiRs,-One cannot, I think, deprecate too strongly the overweening assumption of perfect security from danger for any one method of administering an anæsthetic. I refer to the letter of Mr. C. J. Harris in The LANCET of Dec. 14th, p. 1696. Neither, in my opinion, can one too strongly urge on enthusiasts such as Mr. Harris that, at present at least, we must aim at right administration to the individual, not to "the public." The conception of a perfectly safe anæsthesia to be conferred on all and sundry - be it by any one anæsthetic or by any method of dosage by that anæsthetic-is in our present condition of knowledge a conception only, not a realisation. "There are no rules in medicine," is an adage with a wide application. It cannot be too strongly urged on students that it is only by careful observation of every case that skill in anæsthetic administration can be obtained, and not by the blind adherence to any rule-of-thumb method of administration. Krohne's inhaler is an excellent and most useful apparatus, but it is not, as claimed for it, the solution of the difficulty and dangers of chloroform administration. Any experienced anæsthetist will know that difficulties and dangers arise in the course, say, of severe abdominal operations, which cannot be overcome by any one method, or by any agency save common sense born of experience in the use of all methods. That anyone can in time be anæsthetised by the gradual and methodical use of a Krohne inhaler I am prepared to admit. But that I ought to be able to go to any and every case with no other methods in my head or apparatus in my bag I am not prepared to agree to. Surely, Sirs, difference of opinion in such an important matter does not imply "lack of clear thought" or of observation as Mr. Harris suggests. - I am, Sirs, yours faithfully,

S. HenNing Belfrage, M.D. Lond.

Senior Anxsthetist to the Samaritan Free Hospital.

Montagu-place, W., Dec. 13th, 1901.

\section{THE BRITISH ELECTRO-THERAPEUTIC SOCIETY.}

To the Editors of THE LANCET.

SiRs, - At a meeting held on Dec. 13th it was unanimously decided that a society be formed for the study of electricity in its relation to medical science and that the said society be named "The British Electro-Therapeutic," also that a provisional committee be appointed, to consist of Dr. W. S. Hedley, Dr. Lewis Jones, Dr. H. G. Turney, Dr. J. H. Bryant, Dr. George Herschell, Dr. J. T. Ashton, Dr. H. McClure, and Mr. Chisholm Williams, to take the necessary steps for the organisation of such a society and to report to a meeting to be convened for Jan. 10th, 1902.

I am, Sirs, yours faithfully, Chisholm Williams.

20, Bedford-square, W.C., Dec. 15th, 1901.

\section{DUODENAL ULCER AND ITS SURGICAL TREATMENT.}

To the Editors of THE LANCET.

SIRS,-In speaking of perforation of a duodenal ulcer Mr. B. G. A. Moynihan, in his instructive paper on the subject in THE LANCET of Dec. 14th, p. 1656, indicates the direction which the fluid may be supposed to take--viz., to the hepatic flexure of the colon, along the outer side of the ascending portion, to the iliac fossa, and thence to the pelvis, \&c.

I imagine that this applies to cases of sudden rupture and where much flaid escapes when a person is in the erect position, as in Mr. Moynihan's second case. To give the escaped fluid a chance of remaining localised it would seem in these cases of the utmost value to lay the patient in a recumbent position immediately, and to maintain him there at all costs. One so often sees patients brought to hospital who are suffering from ruptured gastric ulcer in vehicles which do not allow of their lying down. I believe that it is these journeys which are largely responsible for the wide extent of peritoneal infection. Recent inquiries into the anatomy of the right kidney pouch in the cadaver have convinced me of what great importance this area is for the localisation of pus and other fluids, especially those coming from the duodenal region. If the viscera be removed it will be seen that the hollow of the flank, of which the kidney pouch is the most dependent portion, sinks three inches below its lowest boundary wall, which is the brim of the pelvis. Pus or extravasated fluid, unless of very large amount, must find some difficulty in ascending this gradient in order to flow over the brim of the pelvis into its cavity while the patient is supine. And it is correspondingly much easier for appendicitic pus to pass down the flank and infect the kidney pouch. As the kidney pouch with its various diverticula under the liver and into the lesser omental sac is notably difficult to cleanse I should have been glad to have seen Mr. Moynihan recommend an incision at the outer side of the right kidney just below the last rib and drainage at that point. I am, Sirs, yours faithfully,

Birmingham, Dec. 16th, 1901

$$
\text { F. Victor Milward, F.R.C.S. Eng. }
$$

\section{SNALL-POX AND VACCINATION.}

\section{To the Editors of THE LANCET.}

SiRs, - There are many etters written to the medical papers now on the above subject, and some of the remedies sug. gested for inefficient vaccination are amusing if not instructive. Surely at a time when small-pox is daily increasing in 